WORKING PAPER · NO. 2020-115

\title{
What Is CEO Overconfidence? Evidence from Executive Assessments
}

Steven N. Kaplan, Morten Sorensen, and Anastasia A. Zakolyukina AUGUST 2020

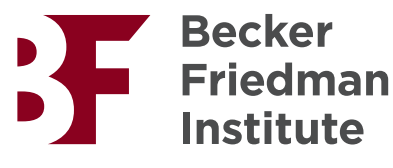




\section{What Is CEO Overconfidence? Evidence from Executive Assessments}

\author{
Steven N. Kaplan
}

\author{
Morten Sorensen
}

August 24, 2020

\author{
Anastasia A. Zakolyukina*
}




\section{Introduction}

Academics and practitioners increasingly believe that CEO personalities, abilities, and characteristics matter for corporate performance. ${ }^{1} \mathrm{CEO}$ overconfidence has received particular attention in corporate finance and economics research because it might lead to suboptimal corporate decisions. Malmendier and Tate (2005a) find that investments by firms led by overconfident CEOs are significantly more sensitive to their cash flows, which is often interpreted as a sign of managerial myopia. Malmendier and Tate (2008) find that overconfident CEOs are more likely to make value-destroying mergers, particularly diversifying ones. ${ }^{2}$

In their survey of CEO and managerial overconfidence, Malmendier and Tate (2015) note that "the most common approach to measuring CEO overconfidence has been to use decisions that the executive makes on his or her personal portfolio of company stock options." The variable, named Longholder by Malmendier and Tate (2005a), classifies CEOs as overconfident when they hold vested options that are at least $40 \%$ in the money until the year the options expire. The intuition is that risk averse CEOs would exercise deep in-themoney options well before expiration to reduce their exposure to company-specific risks and to obtain the benefits of diversification, and that leaving such options outstanding therefore signals overconfidence about the prospects of their firms. Many subsequent papers have used this measure of overconfidence. ${ }^{3}$

There may be other reasons, however, for CEOs not to exercise in-the-money options. For example: (1) Risk-neutral or less risk averse CEOs may choose to take advantage of the tax deferral in options. (2) CEOs can hedge the value of their equity holdings rather than engage in an outright sale of shares or exercise of options. (3) CEOs may believe or know the company stock is undervalued, and rationally do not exercise. (4) CEOs may not be

\footnotetext{
${ }^{1}$ For example, see Bertrand and Schoar (2003), Bloom and Van Reenen (2007), and Kaplan et al. (2012).

${ }^{2}$ Malmendier and Tate (2015) survey the literature on CEO (and managerial) overconfidence. See also Guenzel and Malmendier (2020) who survey the behavioral corporate finance literature on CEOs.

${ }^{3}$ See Bettis et al. (2001), Jagolinzer et al. (2007), and Bettis et al. (2015).
} 
able to exercise options because the board precludes them from doing so. ${ }^{4}$

Given these alternative motivations for not exercising options, we use detailed assessments of executives who become public company CEOs to understand which managerial characteristics are related to Longholder. This, in turn, allows us to consider whether the Longholder measure can be interpreted as reflecting CEO overconfidence.

We obtain personality assessments for more than 2,600 candidates for management positions. The assessments are based on four-hour structured interviews performed by ghSMART, primarily between 2001 and 2012. ${ }^{5}$ After each interview, ghSMART produces a detailed description of the candidate's background and characteristics. The assessments also rate each candidate for 30 specific characteristics and abilities that capture different aspects of the executive's personality. ${ }^{6}$ The assessed executives are typically candidates for $\mathrm{CEO}, \mathrm{CFO}, \mathrm{COO}$, and other top management positions. The firms requesting the assessments are governed under a variety of different ownership forms, including venture capital, private equity-owned, other privately owned, and publicly traded firms.

We track each candidate's subsequent career to determine which candidates subsequently become a CEO of a public company and identify 67 such candidates. Of these 67 CEOs, nine (13\%) are Longholders. This approach allows us to compare the personalities of CEOs classified as Longholders and Non-Longholders.

We find that Longholder CEOs have significantly lower scores on a number of characteristics: having a strong network, being organized and calm under pressure, moving fast, sticking to commitments, having strong analytical skills, being creative, having a strong work ethic, having good listening skills, and being open to criticism. Personalities of CEOs identified as overconfident by the Longholder measure thus exhibit these characteristics to a lesser extent than other CEOs.

This evidence is consistent with the typical characteristics of overconfident individuals

"Some firms adopt "hold to retirement" or "hold past retirement" requirements for equity awards (Larcker and Tayan 2016).

${ }^{5}$ Botelho and Powell (2018) and Botelho et al. (2017) also analyze the ghSMART data.

${ }^{6}$ See Table A-1 in Kaplan and Sorensen (2019). 
identified in the psychology literature. Overconfident individuals have been found to have weaker networks (Burt 1997; Klayman et al. 1999; Hayward et al. 2006; Gudmundsson and Lechner 2013), to be too optimistic with organization, planning, and commitments (Larwood and Whittaker 1977; Vallone et al. 1990), to have lower analytical skills and cognitive ability (Stango et al. 2017; Chapman et al. 2018), and to be worse listeners and feedback seekers (Tost et al. 2012; Meikle et al. 2016). Given that Longholder CEOs exhibit similar characteristics, our evidence is consistent with the interpretation of Longholder as measuring overconfidence.

Because the specific characteristics are highly correlated, Kaplan and Sorensen (2019) use factor analysis to reduce the dimensionality and identify the main variation in the data. In the sample of 2,600 executives, they identify four factors that explain $54 \%$ of the variation across characteristics. They interpret these factors as (1) general talent, (2) execution (vs. interpersonal), (3) charisma (vs. analytical), and (4) strategic (vs. managerial). Interestingly, Longholder is significantly negatively related to the first factor, suggesting that overconfident CEOs tend to have less general talent or ability. This finding is consistent with the classic study (in psychology) by Kruger and Dunning (1999) who show that lower-ability individuals tend to be more overconfident.

We perform three robustness analyses. First, we confirm that firms with Longholder CEOs are similar to firms with non-Longholder CEOs. Second, it is possible that nonLongholders never have a chance to become Longholders, because their options are never sufficiently in-the-money. But we find that the average moneyness of non-Longholders' options is not statistically different from that of Longholders. Third, in addition to the Longholder measure, we explore two alternative measures of overconfidence, namely, the extent to which CEOs provide optimistic earnings guidance and the extent to which earnings guidance is overly precise. We find the former measure, overly optimistic earnings guidance, is also negatively correlated with many individual characteristics and with our measure of CEO ability. 
Finally, we estimate the investment-cash flow regressions from Malmendier and Tate (2005a, 2015) using our sample. We confirm that investments by firms with Longholder CEOs are significantly more sensitive to cash flows. Moreover, we find investments by firm with less talented CEOs are also significantly more sensitive to cash flows. The sensitivity to Longholder remains when we include both variables in a regression.

Combined, then, our findings are consistent with overconfidence being associated with lower general ability, but with Longholder capturing an aspect of overconfidence over and above lower general ability.

One limitation of this study is the small sample. Although we obtain statistically significant results for the main relationships, we are unable to include additional explanatory variables. Another limitation is that ghSMART does not explicitly rate the candidates' overconfidence, and we are not able to relate the Longholder measure to a more direct assessment of each candidate's overconfidence. Despite these limitations, we believe our study is useful, given that our data contain unusually, if not uniquely, rich information about the personalities of public company CEOs.

The paper proceeds as follows. Section 2 describes our data, the assessments, and the measurement of overconfidence. Section 3 explores the correlation between the Longholder measure, measures based on earnings guidance and the assessments. Section 4 explores the correlation with Kaplan and Sorensen (2019) factors. Section 5 considers the relation of investment to cash flow and its correlation with Longholder and the assessment factors. Section 6 concludes.

\section{Data}

\subsection{Assessments}

Our main data are a proprietary set of detailed personality assessments of candidates for top management positions (see also Kaplan et al. 2012; Kaplan and Sorensen 2019). The 
assessments are performed by ghSMART, a consulting firm that is engaged by investors, company boards, and company management teams to assess candidates for management positions. Importantly, ghSMART is not an executive recruiting firm, and it does not suggest which candidate(s) to consider for a given position. ghSMART does not receive a fee contingent on whether a candidate is hired, and has no apparent incentives to deliver biased assessments. According to ghSMART, its main concern is to provide accurate assessments to maintain its reputation and generate repeat business. Note that the assessments are performed ex ante, typically before the candidate becomes CEO, which by itself could influence the candidate's personality and overconfidence.

ghSMART's assessments are based on extensive structured interviews. During the interview, the interviewer ${ }^{7}$ asks for specific examples of the candidate's actions and behavior at previous jobs and life stages, starting with the candidate's childhood and progressing through the candidate's education and subsequent career path. The candidate's history and behavior is summarized in a 20- to 40-page report, which is effectively a mini-biography of the candidate.

In addition to the narrative part, each report also includes ratings for 30 specific characteristics across five general areas, which are classified by ghSMART as Leadership, Personal, Intellectual, Motivational, and Interpersonal. Table A-1 in Kaplan and Sorensen (2019) shows an excerpt from ghSMART's internal guidelines that describe the 30 characteristics along with the behaviors that determine their scoring. ${ }^{8}$ Appendix A in this paper lists the 30 characteristics and five general areas. In many of the assessments, the ratings for oral and written communications are absent. Accordingly, we do not include these two characteristics in our analyses. The reports sometimes include ratings for other characteristics that are specific to a particular firm or situation, but because these characteristics are

\footnotetext{
${ }^{7}$ The ghSMART interviewers generally hold doctoral degrees or degrees from top MBA programs, and have worked at consulting firms (e.g., McKinsey \& Co., Bain, and Boston Consulting Group). ghSMART reports a high degree of consistency of assessments across interviewers.

${ }^{8}$ Smart and Street (2008) provide additional information and detail about ghSMART's interviewing methodology.
} 
not consistently reported across candidates, we do not include them in our analysis.

An important concern is whether the candidates can "game" or "fake" the interviews by providing answers they believe will help them be hired, even if they do not reflect their actual personalities. The ghSMART assessments and ratings appear to be reliable for a number of reasons. The assessments are formed using best practices from organizational psychology, including using external interviewers not self-assessments, and using extensive structured interviews rather than questionnaires. In organizational psychology, these practices have been found to produce assessments that are consistent across tests and robust to gaming and faking by the test subjects. ghSMART charges more than $\$ 20,000$ per assessment and has seen its business grow substantially, suggesting that ghSMART's customers find the assessments useful. ${ }^{9}$ Finally, it is difficult to reconcile the empirical results with significant faking. If the assessments were uninformative, we would not see the statistical relationships between the assessed characteristics and various outcomes that are documented in Kaplan et al. (2012), Kaplan and Sorensen (2019) and this paper. For example, Kaplan and Sorensen (2019) find that the scores predict which candidates later become CEOs and CFOs, suggesting that the assessed characteristics are, at least somewhat, persistent and reflect the candidates' personalities as perceived in other hiring and recruiting situations that do not involve ghSMART.

It should be noted that at the time of the assessments, ghSMART and the candidates would not have been aware of the factor structure and other results we report.

\subsection{Factors}

The assessments grade the executives on the 28 specific characteristics we use, with a rating from D (lowest) to A+ (highest), reflecting the extent to which the candidate's

\footnotetext{
${ }^{9}$ Additionally, albeit anecdotally, several PE firms told us they do not make any investments without a $\mathrm{CEO}$ assessment of the type ghSMART provides. Although economic theory suggests it may be rational for candidates to attempt to misrepresent their types, economic theory also prescribes that it would be irrational for investors to rely on such assessments if they were uninformative. Assessments also are costly: in addition to the fee charged by ghSMART, assessments require at least four hours of a candidate's time.
} 
personality exhibit the specific characteristic. We convert these letter grades to numerical scores by coding all grades of B or below as 1 (we combine these grades because we have relatively few of them). We code grades of $\mathrm{B}+$ as 2 and grades of $\mathrm{A}$ - as 3 . We code grades of $\mathrm{A}$ and $\mathrm{A}+$ as 4, because we find relatively few A+'s. The results are not sensitive to the coding scheme.

The ratings for the characteristics are highly correlated, making it difficult to infer the effects of individual characteristics in a multivariate analysis. Kaplan and Sorensen (2019) use factor analysis to identify four factors with eigenvalues above one, which combined capture most of the variation in the candidates' characteristics. The loadings of the individual characteristics on the four factors are shown in Appendix B, and these loadings lend themselves to natural interpretations of the factors. The first factor has positive loadings on all the specific characteristics, and this factor can be interpreted as a CEO's general ability in the spirit of Rosen (1981). This structure of this first factor is common in factor analysis, dating back to Spearman's g-factor (Spearman 1904), and it reflects the general tendency of characteristics to move together.

The second factor loads on two distinct sets of characteristics. The more positive loadings, in decreasing order, are for Respect, Open to criticism, Listening skills, and Teamwork. These characteristics capture a candidate's communication and interpersonal skills. By contrast, the more negative loadings are for Aggressive, Fast, Proactive, Holds people accountable, and Removes underperformers. These characteristics arguably reflect a candidate's execution ability. The second factor therefore sorts candidates into those with better interpersonal skills versus those with greater execution ability. Those with greater interpersonal skills have positive scores, and those with greater execution ability have negative scores.

The third factor has the most negative loadings for Enthusiasm, Persuasion, Aggressive, Proactive, and Fast. These characteristics appear to describe more charismatic candidates. By contrast, the most positive loadings are for Analytical skills, Attention to detail, Orga- 
nization, and Brainpower, which describe candidates with more analytical personalities. The third factor can therefore be interpreted as sorting candidates into those with more charismatic personalities, who have negative scores on this factor, versus candidates with more analytical skills, who have positive scores on this factor.

Finally, the fourth factor has the most positive loadings for Strategic vision, Brainpower, Analytical skills, and Creative. These characteristics arguably describe candidates with more high-level and strategic perspectives. It has the more negative loadings on Holds people accountable, Efficiency, Attention to detail, and Organization, which are associated with more managerial and detail-oriented personalities. The fourth factor thus differentiates between candidates with a higher-level and strategic perspective, who have positive scores on this factor, versus those with a managerial and detail-oriented personality, who have negative scores.

Kaplan and Sorensen (2019) compare the scores for CEO and CFO candidates. CEO candidates score higher on the first factor (more general talent), more negatively on the second factor (more execution), more negatively on the third factor (more charismatic), and more positively on the fourth factor (more strategic). By contrast, the scores of CFO candidates tend to have the opposite signs. CFOs tend to score lower on the first factor (less general talent), higher on the second factor (more interpersonal), substantially higher on the third factor (more analytical), and lower on the fourth factor (more detail-oriented and managerial).

\subsection{Overconfidence measures}

Managerial overconfidence has traditionally been defined in two ways (Malmendier and Tate 2015; Bénabou and Tirole 2016): (a) as optimism, that is, overestimation of one's absolute performance (overestimation) or relative performance (overplacement) (e.g., Heaton 2002; Malmendier and Tate 2005a; Ben-David et al. 2013); and (b) as overprecision, 
that is, excessive precision in one's beliefs (e.g., Hackbarth 2008; Ben-David et al. 2013). ${ }^{10}$

Because managerial overconfidence is difficult to measure directly outside of a survey setting (as in Ben-David et al. 2013; Graham et al. 2013), the literature has used several indirect measures. Overconfidence in terms of optimism-overestimation of the mean outcome-has been measured using the option-based approach (e.g., Malmendier and Tate 2005a,b, 2008), the earnings-forecast-based approach (e.g., Huang and Kisgen 2013; Otto 2014), and the press-based approach (e.g., Malmendier and Tate 2008; Hirshleifer et al. 2012). ${ }^{11}$ The press-based approach requires an extensive search of media coverage for each individual executive. By contrast, the option-based measures use executives' option holdings data, and the earnings-forecast-based measures use firms' reported earnings and earnings guidance data, which are available for public firms. The option-based Longholder measure is probably the most widely used measure of overconfidence (Malmendier 2018).

For overprecision, Ben-David et al. (2013) use a quarterly survey of CFOs' forecasts of the S\&P 500. Moreover, firms can specify a range forecast or a point estimate when disclosing their earnings guidance, and more confident CEOs might provide a narrower forecast range or a point estimate. Indeed, about two-thirds of firms provide a range forecast (e.g., Otto 2014), and Huang and Kisgen (2013) suggest that the width of this range reflects the confidence in the forecast.

\subsubsection{Longholder measure}

To relate the CEOs' assessed personalities to measures of overconfidence, we manually augment the assessment data with information about each candidate's subsequent career, using LinkedIn, Bloomberg, and other web searches. We identify 67 individuals who eventually become public company CEOs. Figure 1 shows the industries of the 78 firms that these candidates worked for. Most of the firms are in information technology, health care, consumer discretionary, and industrials.

\footnotetext{
${ }^{10}$ Moore and Healy (2008) reconciles these definitions of overconfidence.

${ }^{11}$ Malmendier (2018) discusses these measures in detail.
} 
For the candidates identified as public company CEOs, we obtain their equity and option portfolio holdings from DEF 14A filings in the SEC EDGAR database, which enables us to compute the Longholder measure from Malmendier and Tate (2015). Longholder is an indicator that equals 1 for CEOs who hold an option to the last year before expiration, provided it was at least $40 \%$ in-the-money entering the final year. Nine of the 67 CEOs $(13 \%)$ are Longholders.

\subsubsection{Measures based on earnings guidance}

We collect earnings (EPS) forecasts and realizations from IBES. Our sample contains 31 CEOs with multiple quarters per CEO, providing a total of $216 \mathrm{CEO}$-quarter observations. We create two additional measures of overconfidence from these observations. As in Otto (2014), we create an indicator variable, High Forecast, that equals 1 when a firm's EPS forecast exceeds realized EPS. If a firm provides an EPS range forecast rather than a point estimate, High Forecast equals 1 if the lower bound of the range exceeds the realized EPS. High Forecast therefore provides a measure of a CEO being optimistic about earnings.

We also follow Huang and Kisgen (2013) and create another indicator, called Point Estimate, that equals 1 when a firm provides a point EPS forecast, and equals 0 when it provides a range EPS forecast.

\subsection{Endogeneity of longholders}

A concern is that Longholder firms and Longholder CEOs are endogenously matched, and that differences between Longholder and other CEOs may partly be due to differences in their firms rather than differences in their overconfidence. In Table 1, we compare firm characteristics of Longholder and non-Longholder firms. The table shows that the two sets of firms do not differ statistically on firm characteristics-including market value, sales, $\mathrm{ROA}, \mathrm{Q}$, investment, and leverage.

The only exception is that Longholder CEOs hold a greater fraction of equity in their 
firms both in stock and vested options, consistent with the interpretation that Longholder reflects overconfidence. Indeed, the model in Gervais et al. (2011) shows that an overconfident manager is more likely to accept a highly convex compensation contract because the manager is more likely to overvalue it. Humphery-Jenner et al. (2016) provide supportive empirical evidence by finding that overconfident CEOs are more likely to receive incentive-based pay that relies on stock options.

Another concern is whether non-Longholder CEOs actually have an opportunity to exercise in-the-money options and choose not to do so. The Longholder measure would be noisier if the options of CEOs classified as non-Longholder were never actually in-themoney. Accordingly, Table 2 reports the vested options and their average moneyness for both groups of CEOs. Longholder CEOs have less vested option holdings, in terms of both their Black-Scholes and intrinsic values. However, the average moneyness of nonLongholders options is not statistically different from that of Longholders, even for the vested options that are at least 40\% in-the-money. Hence, non-Longholders did have a chance to become Longholders. Moreover, the dollar value of option tranches that Longholders hold for too long is not negligible. For the vested options at least $40 \%$ in-the-money in the last year before expiration, the mean (median) Black-Scholes values is $\$ 1.29$ (\$1.15) million and the intrinsic value is $\$ 2.08$ ( $\$ 1.24)$ million.

\section{Individual characteristics}

In this section, we consider how the Longholder measure and other measures of overconfidence relate to individual characteristics and aspects of personalities. Table 3 compares ratings on the characteristics for Longholder and non-Longholder CEOs. We see that Longholder is negatively related to most of the specific characteristics. The differences are significant for having a strong network, being organized, calm under pressure, moving fast, sticking to commitments, having strong analytical skills, being creative, having a strong

work ethic, good listening skills, and being open to criticism. Longholder CEOs therefore 
exhibit these characteristics to a lesser extent than non-Longholder CEOs.

\subsection{Characteristics and behavior of overconfident individuals}

An extensive psychology literature examines the typical characteristics and behavior of overconfident individuals. Below, we review this literature. Appendix A lists the expected relations between overconfidence and the specific characteristics in our assessments.

Overconfident individuals tend to search too little for ideas and information (Haran et al. 2013; Moore et al. 2015). They have more "constrained" social networks that are smaller and more interconnected with weaker connections to outsiders (Burt 1997; Klayman et al. 1999; Hayward et al. 2006; Gudmundsson and Lechner 2013), which can reinforce overconfident leaders being less likely to see flaws and having inflated expectations of positive outcomes (Shipman and Mumford 2011). Consistent with this literature, we find that overconfident CEOs are less likely to have a strong network.

Overconfident individuals also tend to be less organized, to plan less, and to be less likely to stick to commitments. Their limited ability to see deficiencies and to expect positive outcomes can lead to less time and effort invested in learning and planning (Shipman and Mumford 2011). Indeed, Vancouver and Kendall (2006) find that high self-efficacy_one's belief in his or her capacity to perform-has a negative effect on preparation. Similar negative effects of overconfidence on organization and planning are also found elsewhere (Larwood and Whittaker 1977; Vallone et al. 1990). For instance, Larwood and Whittaker (1977) find that the general belief among managers that their own firms would possess unusually high growth rates led to overly optimistic planning. Our findings are consistent with this literature.

Despite overly optimistic planning, overconfident individuals score high on social potency, which includes being forceful and decisive, and low on stress reaction (Burks et al. 2013). This finding suggests that overconfident CEOs should score high on being calm under pressure and moving fast. We do not find these positive associations. 
Overconfident individuals tend to rank lower on analytical skills and cognitive ability. Pallier et al. (2002) suggest that higher intelligence is associated with less overconfidence. Supporting this result, Chapman et al. (2018) find a negative correlation between IQ (and cognitive ability) and overconfidence; and Stango et al. (2017) find a positive correlation with math biases, such as non-belief in the law of large numbers (Benjamin et al. 2013), gambler's fallacy/hot-hand fallacy (Benjamin et al. 2013), exponential-growth bias (Stango and Zinman 2009; Banks and Oldfield 2007), and overconfidence. Consistent with this literature, we find overconfident CEOs rank lower on analytical skills.

Although overconfidence is found to be negatively correlated with analytical skills and cognitive ability, the evidence for creativity (Hirshleifer et al. 2012; Stock et al. 2019) and a strong work ethic (Bénabou and Tirole 2002; Heidhues et al. 2018) is mixed. Overconfidence has been found to be related to proactiveness (Pallier et al. 2002) and extraversion (Schaefer et al. 2004). These traits are arguably related to enthusiasm and optimistic expectations. In studying entrepreneurship, Hayward et al. (2006) argue that greater overconfidence provides venture founders with the bravado to persist. Indeed, overconfident individuals with high self-esteem tend to persist for too long even when this persistence is not productive (McFarlin et al. 1984). This persistence can be supported by working harder. For instance, theoretical work on overconfidence has emphasized that if ability and effort are complements, overconfidence can lead to higher effort (Bénabou and Tirole 2002; Gervais et al. 2011). By contrast, a model by Heidhues et al. (2018) suggests that if the complementarity between ability and effort is low or ability and effort have separable effects, overconfidence can lead to lower effort. We find a negative association for both creativity and work ethic.

The literature has also found robust evidence for overconfidence being negatively related to listening skills and being open to criticism. Overconfident individuals tend to underinvest in information acquisition, such as seeking advice, and often blame failures on uncontrollable factors (Meikle et al. 2016). Moreover, a feeling of power leads them to discount advice and exacerbates the feelings of higher optimism, control, and over- 
confidence (Tost et al. 2012). To the extent that research findings for narcissism apply to overconfidence, ${ }^{12}$ these individuals dismiss advice because they think others are incompetent and because they fail to reduce their self-enhancement when expecting to be assessed (Kausel et al. 2015; Littrell et al. 2019). Consistent with this literature, we find a negative relation between overconfidence and listening skills.

\subsection{Earnings forecasts and individual characteristics}

Table 4 reports regression results of the two EPS-based measures of overconfidence against the specific characteristics. Because this sample contains several quarterly observations for each CEO, we cluster standard errors by CEO. Similar to Longholder, High Forecast is negatively related to most of the individual characteristics and significantly so to several of them. Sticking to commitments, brainpower, and being creative are significantly negative for both Longholder and High Forecast, consistent with Larwood and Whittaker (1977), Vallone et al. (1990), Stango et al. (2017), Chapman et al. (2018), and Stock et al. (2019).

Unlike Longholder, Point Estimate is sometimes positively and negatively related to the individual characteristics.

Overall, this evidence suggests that the notion of overconfidence that is captured by Longholder is closer to that of High Forecast. They both appear to differ markedly from the overprecision captured by Point Estimate.

\section{Overconfidence and general ability}

As mentioned earlier, Kaplan and Sorensen (2019) show that the variation in the specific characteristics can be summarized by four factors. Table 5 reports the means and distributions for the four factors for all CEOs, and for non-Longholder and Longholder CEOs. Table 6 reports the correlations between Longholder and the four factors.

\footnotetext{
${ }^{12}$ For example, see Campbell et al. (2004), Shipman and Mumford (2011), Macenczak et al. (2016), and Littrell et al. (2019).
} 
Both in univariate and multivariate regressions, Longholder is negatively related to all four factors, but is significantly negatively correlated with only the first factor. The first factor has positive loadings on all specific characteristics. Kaplan et al. (2012) interpret it as a measure of general talent or ability. They also find that it is correlated with subsequent CEO success.

Interestingly, this finding that overconfident CEOs (as measured by Longholder) have lower general ability is consistent with the well-known Dunning-Kruger effect in psychology. Kruger and Dunning (1999) document that less competent people tend to overestimate their abilities more than those who are more skilled. ${ }^{13}$ The stronger overestimation by less competent people can occur because their lack of competence deprives them of the metacognitive ability to realize they make mistakes. As Kruger and Dunning (1999) write, "When people are incompetent in the strategies they adopt to achieve success and satisfaction, they suffer a dual burden: Not only do they reach erroneous conclusions and make unfortunate choices, but their incompetence robs them of the ability to realize it" (p. 1121). This positive relation between overconfidence and the lack of skill persists even when people receive accurate feedback on their performance (Simons 2013) and are held accountable for their self-assessments (Ehrlinger et al. 2008). The Dunning-Kruger effect has been found not only among students and laymen, but also among professionals with specialized knowledge. For instance, high-performing medical doctors significantly underestimate their performance, whereas low-performing medical doctors significantly overestimate their performance (Hodges et al. 2001; Davis et al. 2006; Mehdizadeh et al. 2014). Our results suggest that this effect holds for CEOs as well.

In Table 7, High Forecast, like Longholder, is significantly negatively related to Factor 1 both in univariate and multivariate regressions, suggesting, again, that overconfidence is related to lower overall ability (Kruger and Dunning 1999). High Forecast is significantly negatively related to Factor 3 (positively related to charisma), but this relation is

\footnotetext{
${ }^{13}$ Dunning (2011) reviews research on the Dunning-Kruger effect.
} 
insignificant in a multivariate regression. In the multivariate regression, High Forecast is marginally significantly related to Factor 2 (lower execution skills) and Factor 4 (greater creative / strategic). The result for Factor 2 is consistent with overconfidence being related to lower execution ability.

\section{Investment-cash flow sensitivities}

The relationships we document between managerial overconfidence-as captured by Longholder and High Forecast — and executive characteristics are consistent with two different interpretations of the empirically documented behavior of Longholder CEOs. Longholder is related to variables that are associated with overconfidence, and it may capture behavior of overconfident CEOs, as it is typically interpreted. At the same time, Longholder and overconfidence are also related to lower general ability, so Longholder may also capture behavior of less able CEOs.

Although our limited data make this part of our analysis somewhat tentative and suggestive, we try to distinguish between these two interpretations by revisiting the empirical findings on investment-cash flow sensitivities from Malmendier and Tate (2005a) and Malmendier and Tate (2015). Following their analyses, we collect information about investment and cash flow, along with a number of other accounting variables, for the public firms with CEOs in our sample. Descriptive statistics for these variables are in Table 8. Table 9 reports the estimates of the investment-cash flow regression (used in the Malmendier and Tate papers) for our sample.

The first column of Table 9 shows that, despite the small sample, we replicate the main Longholder results, and we confirm that investments in companies with Longholder CEOs are significantly more sensitive to their cash flows, although the significance is only at the $10 \%$ level. In the second column of Table 9 , we see that investments are less sensitive to cash flows when CEOs have greater general talent (higher Factor 1), which suggests that investments are more sensitive to cash flow when CEOs have less general talent and 
ability. Columns three to five in Table 9 estimate the investment-cash flow sensitivities for the remaining three factors individually. Interestingly, the results indicate that the investment-cash flow sensitivities are also greater for firms with more analytical CEOs (positive Factor 3) and with more operational and managerial CEOs (negative Factor 4).

In the multivariate specification, only the third factor remains statistically significant. Importantly, however, the coefficient for Longholder also remains significant even when the other factors are included. This result suggests that the empirical effect of Longholder is not merely an artifact of this variable being related to other aspects of managerial personalities, as captured by the four factors, but that Longholder captures a distinct aspect of individual overconfidence as it is usually interpreted in the literature.

\section{Conclusion}

We use detailed assessments of CEOs to explore the nature of Longholder, the optionbased measure of CEO overconfidence introduced by Malmendier and Tate (2005a) and now commonly used in the corporate finance and economics literatures. We document a pattern of correlations between the Longholder measure and individual characteristics that prior literature has found to be related to overconfidence. Longholder CEOs are less likely to have strong networks (e.g., Burt 1997; Klayman et al. 1999; Hayward et al. 2006). They are less likely to be well organized and to honor commitments (e.g., Larwood and Whittaker 1977; Vallone et al. 1990). They tend to have lower analytical skills and cognitive ability (e.g., Stango et al. 2017; Chapman et al. 2018), and tend not to be good listeners or feedback seekers (e.g., Tost et al. 2012; Meikle et al. 2016). Finally, Longholder and a measure of overconfidence based on high earnings forecasts are negatively related to overall CEO ability/talent; that is, less talented CEOs appear to be more overconfident (Kruger and Dunning 1999).

These results provide solid evidence that Longholder measures a quality that is related to overconfidence and adds to our understanding of the nature of that overconfidence. 


\section{References}

Banks, James, and Zoë Oldfield, 2007, Understanding pensions: Cognitive function, numerical ability and retirement saving, Fiscal Studies 28, 143-170.

Ben-David, Itzhak, John R. Graham, and Campbell R. Harvey, 2013, Managerial miscalibration, Quarterly Journal of Economics 128, 1547-1584.

Bénabou, Roland, and Jean Tirole, 2002, Self-confidence and personal motivation, Quarterly Journal of Economics 117, 871-915.

Bénabou, Roland, and Jean Tirole, 2016, Mindful economics: The production, consumption, and value of beliefs, Journal of Economic Perspectives 30, 141-64.

Benjamin, Daniel, Don Moore, and Matthew Rabin, 2013, Misconceptions of chance: Evidence from an integrated experiment, Working Paper .

Bertrand, Marianne, and Antoinette Schoar, 2003, Managing with style: The effect of managers on firm policies, Quarterly Journal of Economics 118, 1169-1208.

Bettis, Carr, John Bizjak, and Swaminathan Kalpathy, 2015, Why do insiders hedge their ownership? An empirical examination, Financial Management 44, 655-683.

Bettis, J. Carr, John M. Bizjak, and Michael L. Lemmon, 2001, Managerial ownership, incentive contracting, and the use of zero-cost collars and equity swaps by corporate insiders, Journal of Financial and Quantitative Analysis 36, 345-370.

Bloom, Nicholas, and John Van Reenen, 2007, Measuring and explaining management practices across firms and countries, Quarterly Journal of Economics 122, 1351-1408.

Botelho, Elena, and Kim Powell, 2018, The CEO Next Door: What It Takes to Get to the Top and Succeed. (Dickens Books).

Botelho, Elena Lytkina, Kim Rosenkoetter Powell, Stephen Kincaid, and Dina Wang, 2017, What sets successful CEOs apart?, Harvard Business Review 95, 70-77.

Burks, Stephen V., Jeffrey P. Carpenter, Lorenz Goette, and Aldo Rustichini, 2013, Overconfidence and social signalling, Review of Economic Studies 80, 949-983.

Burt, Ronald S., 1997, The contingent value of social capital, Administrative Science Quarterly 339-365.

Campbell, W Keith, Adam S Goodie, and Joshua D Foster, 2004, Narcissism, confidence, and risk attitude, Journal of behavioral decision making 17, 297-311.

Chapman, Jonathan, Mark Dean, Pietro Ortoleva, Erik Snowberg, and Colin Camerer, 2018, Econographics, NBER Working Paper No. 24931. 
Davis, David A., Paul E. Mazmanian, Michael Fordis, Rtke Van Harrison, Kevin E. Thorpe, and Laure Perrier, 2006, Accuracy of physician self-assessment compared with observed measures of competence: a systematic review, JAMA 296, 1094-1102.

Dunning, David, 2011, The Dunning-Kruger effect: On being ignorant of one's own ignorance, in Advances in Experimental Social Psychology, volume 44, 247-296 (Elsevier).

Ehrlinger, Joyce, Kerri Johnson, Matthew Banner, David Dunning, and Justin Kruger, 2008, Why the unskilled are unaware: Further explorations of (absent) self-insight among the incompetent, Organizational Behavior and Human Decision Processes 105, 98-121.

Gervais, Simon, James B. Heaton, and Terrance Odean, 2011, Overconfidence, compensation contracts, and capital budgeting, Journal of Finance 66, 1735-1777.

Graham, John R., Campbell R. Harvey, and Manju Puri, 2013, Managerial attitudes and corporate actions, Journal of Financial Economics 109, 103-121.

Gudmundsson, Sveinn Vidar, and Christian Lechner, 2013, Cognitive biases, organization, and entrepreneurial firm survival, European Management Journal 31, 278-294.

Hackbarth, Dirk, 2008, Managerial traits and capital structure decisions, Journal of Financial and Quantitative Analysis 43, 843-881.

Haran, Uriel, Ilana Ritov, and Barbara A. Mellers, 2013, The role of actively open-minded thinking in information acquisition, accuracy, and calibration, Judgment and Decision Making 8, 188-201.

Hayward, Mathew L.A., Dean A. Shepherd, and Dale Griffin, 2006, A hubris theory of entrepreneurship, Management Science 52, 160-172.

Heaton, James B., 2002, Managerial optimism and corporate finance, Financial Management 33-45.

Heidhues, Paul, Botond Kőszegi, and Philipp Strack, 2018, Unrealistic expectations and misguided learning, Econometrica 86, 1159-1214.

Hirshleifer, David, Angie Low, and Siew Hong Teoh, 2012, Are overconfident CEOs better innovators?, Journal of Finance 67, 1457-1498.

Hodges, Brian, Glenn Regehr, and Dawn Martin, 2001, Difficulties in recognizing one's own incompetence: Novice physicians who are unskilled and unaware of it, Academic Medicine 76, S87-S89.

Huang, Jiekun, and Darren J. Kisgen, 2013, Gender and corporate finance: Are male executives overconfident relative to female executives?, Journal of Financial Economics $108,822-839$.

Humphery-Jenner, Mark, Ling Lei Lisic, Vikram Nanda, and Sabatino Dino Silveri, 2016, Executive overconfidence and compensation structure, Journal of Financial Economics 119, 533-558. 
Jagolinzer, Alan D., Steven R. Matsunaga, and P. Eric Yeung, 2007, An analysis of insiders' use of prepaid variable forward transactions, Journal of Accounting Research 45, 1055-1079.

Kaplan, Steven N., Mark M. Klebanov, and Morten Sorensen, 2012, Which CEO characteristics and abilities matter?, Journal of Finance 67, 973-1007.

Kaplan, Steven N., and Morten Sorensen, 2019, Are CEOs different? Characteristics of top managers, NBER Working Paper No. 23832.

Kausel, Edgar E., Satoris S. Culbertson, Pedro I. Leiva, Jerel E. Slaughter, and Alexander T. Jackson, 2015, Too arrogant for their own good? Why and when narcissists dismiss advice, Organizational Behavior and Human Decision Processes 131, 33-50.

Klayman, Joshua, Jack B. Soll, Claudia Gonzalez-Vallejo, and Sema Barlas, 1999, Overconfidence: It depends on how, what, and whom you ask, Organizational Behavior and Human Decision Processes 79, 216-247.

Kruger, Justin, and David Dunning, 1999, Unskilled and unaware of it: How difficulties in recognizing one's own incompetence lead to inflated self-assessments., Journal of Personality and Social Psychology 77, 1121.

Larcker, David, and Brian Tayan, 2016, Corporate governance matters: A closer look at organizational choices and their consequences (Pearson education).

Larwood, Laurie, and William Whittaker, 1977, Managerial myopia: Self-serving biases in organizational planning., Journal of Applied Psychology 62, 194.

Littrell, Shane, Jonathan Fugelsang, and Evan F. Risko, 2019, Overconfidently underthinking: Narcissism negatively predicts cognitive reflection, Thinking $\mathcal{E}$ Reasoning 1-29.

Macenczak, Lee A., Stacy Campbell, Amy B. Henley, and W. Keith Campbell, 2016, Direct and interactive effects of narcissism and power on overconfidence, Personality and Individual Differences 91, 113-122.

Malmendier, Ulrike, 2018, Behavioral corporate finance, NBER Working Paper No. 25162.

Malmendier, Ulrike, and Geoffrey Tate, 2005a, CEO overconfidence and corporate investment, Journal of Finance 60, 2661-2700.

Malmendier, Ulrike, and Geoffrey Tate, 2005b, Does overconfidence affect corporate investment? CEO overconfidence measures revisited, European Financial Management 11, 649-659.

Malmendier, Ulrike, and Geoffrey Tate, 2008, Who makes acquisitions? CEO overconfidence and the market's reaction, Journal of Financial Economics 89, 20-43.

Malmendier, Ulrike, and Geoffrey Tate, 2015, Behavioral CEOs: The role of managerial overconfidence, Journal of Economic Perspectives 29, 37-60. 
McFarlin, Dean B., Roy F. Baumeister, and Jim Blascovich, 1984, On knowing when to quit: Task failure, self-esteem, advice, and nonproductive persistence, Journal of Personality 52, 138-155.

Mehdizadeh, Leila, Alison Sturrock, Gil Myers, Yasmin Khatib, and Jane Dacre, 2014, How well do doctors think they perform on the General Medical Council's Tests of Competence pilot examinations? A cross-sectional study, BMJ open 4, e004131.

Meikle, Nathan L., Elizabeth R. Tenney, and Don A. Moore, 2016, Overconfidence at work: Does overconfidence survive the checks and balances of organizational life?, Research in Organizational Behavior 36, 121-134.

Moore, Don A., and Paul J. Healy, 2008, The trouble with overconfidence., Psychological Review 115, 502.

Moore, Don A., Elizabeth R. Tenney, and Uriel Haran, 2015, Overprecision in judgment, The Wiley Blackwell Handbook of Judgment and Decision Making 182-209.

O'Reilly III, Charles A., and Bernadette Doerr, 2020, Conceit and deceit: Lying, cheating, and stealing among grandiose narcissists, Personality and Individual Differences 154, 109627.

O'Reilly III, Charles A, Bernadette Doerr, and Jennifer A Chatman, 2018, "See you in court": How CEO narcissism increases firms' vulnerability to lawsuits, The Leadership Quarterly $29,365-378$.

Otto, Clemens A., 2014, CEO optimism and incentive compensation, Journal of Financial Economics 114, 366-404.

Pallier, Gerry, Rebecca Wilkinson, Vanessa Danthiir, Sabina Kleitman, Goran Knezevic, Lazar Stankov, and Richard D. Roberts, 2002, The role of individual differences in the accuracy of confidence judgments, The Journal of General Psychology 129, 257-299.

Rosen, Sherwin, 1981, The economics of superstars, American Economic Review 71, 845-858.

Schaefer, Peter S., Cristina C. Williams, Adam S. Goodie, and W. Keith Campbell, 2004, Overconfidence and the Big Five, Journal of Research in Personality 38, 473-480.

Schrand, Catherine M., and Sarah L.C. Zechman, 2012, Executive overconfidence and the slippery slope to financial misreporting, Journal of Accounting and Economics 53, 311-329.

Schwardmann, Peter, and Joel Van der Weele, 2019, Deception and self-deception, Nature: Human Behaviour 3, 1055-1061.

Shipman, Amanda S., and Michael D. Mumford, 2011, When confidence is detrimental: Influence of overconfidence on leadership effectiveness, The Leadership Quarterly 22, 649_ 665.

Simons, Daniel J., 2013, Unskilled and optimistic: Overconfident predictions despite calibrated knowledge of relative skill, Psychonomic Bulletin E Review 20, 601-607. 
Smart, Geoff, and Randy Street, 2008, Who: The A Method for Hiring (Ballantine Books).

Smith, Megan K., Robert Trivers, and William von Hippel, 2017, Self-deception facilitates interpersonal persuasion, Journal of Economic Psychology 63, 93-101.

Solda, Alice, Changxia Ke, Lionel Page, and William Von Hippel, 2019, Strategically delusional, Experimental Economics 1-28.

Spearman, Charles, 1904, 'general intelligence,' objectively determined and measured, The American Journal of Psychology 15, 201-293.

Stango, Victor, Joanne Yoong, and Jonathan Zinman, 2017, The quest for parsimony in behavioral economics: New methods and evidence on three fronts, NBER Working Paper No. 23057 .

Stango, Victor, and Jonathan Zinman, 2009, Exponential growth bias and household finance, Journal of Finance 64, 2807-2849.

Stock, Ruth, Matthias Groß, and Katherine R. Xin, 2019, Will self-love take a fall? Effects of top executives' positive self-regard on firm innovativeness, Journal of Product Innovation Management 36, 41-65.

Tang, Yi, Jiatao Li, and Hongyan Yang, 2015, What I see, what I do: How executive hubris affects firm innovation, Journal of Management 41, 1698-1723.

Tost, Leigh Plunkett, Francesca Gino, and Richard P. Larrick, 2012, Power, competitiveness, and advice taking: Why the powerful don't listen, Organizational Behavior and Human Decision Processes 117, 53-65.

Vallone, Robert P., Dale W. Griffin, Sabrina Lin, and Lee Ross, 1990, Overconfident prediction of future actions and outcomes by self and others, Journal of Personality and Social Psychology 58, 582.

Vancouver, Jeffrey B., and Laura N. Kendall, 2006, When self-efficacy negatively relates to motivation and performance in a learning context, Journal of Applied Psychology 91, 1146.

Yin, Xile, Jianbiao Li, and Te Bao, 2019, Does overconfidence promote cooperation? Theory and experimental evidence, Journal of Behavioral and Experimental Economics 79, 119-133. 


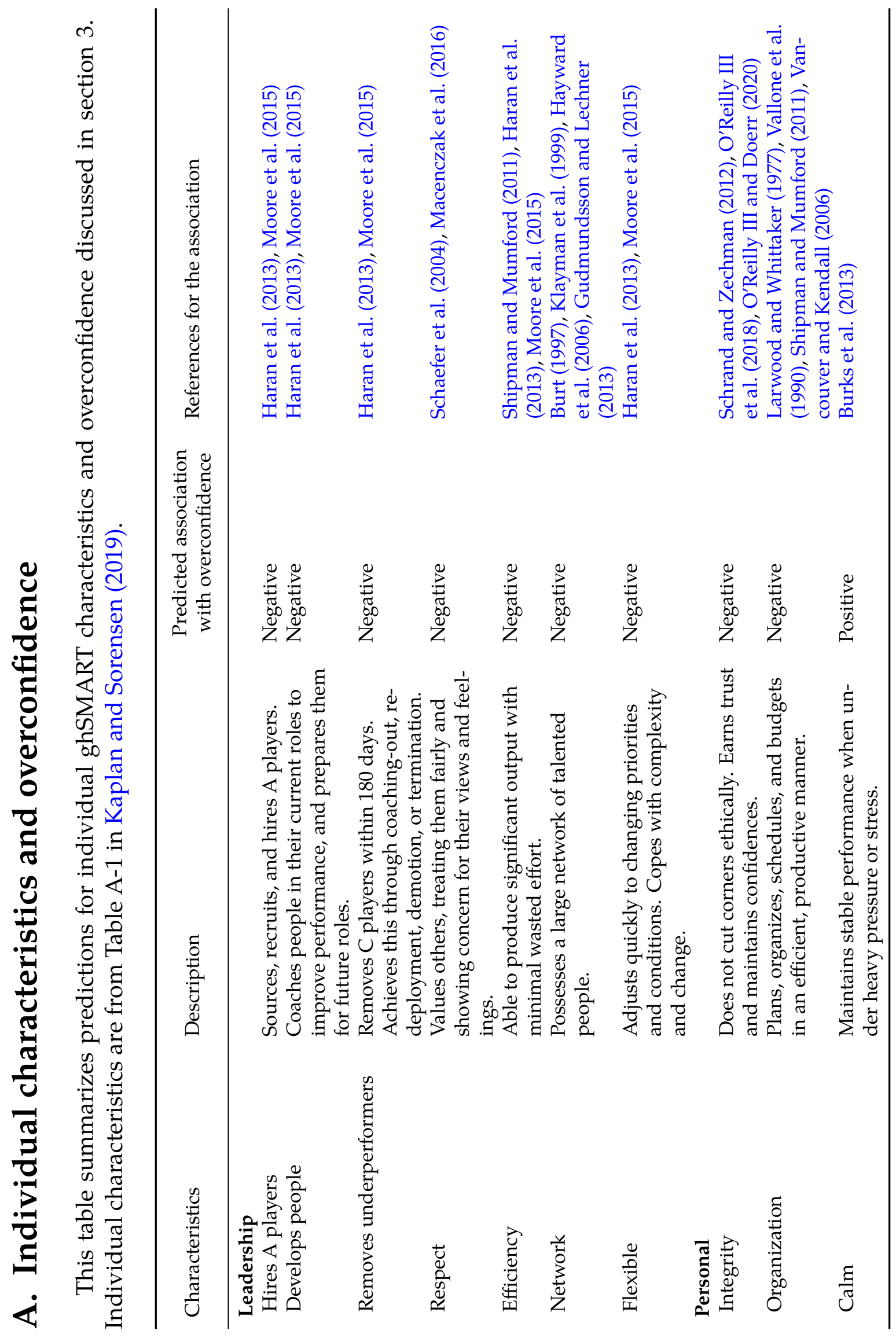




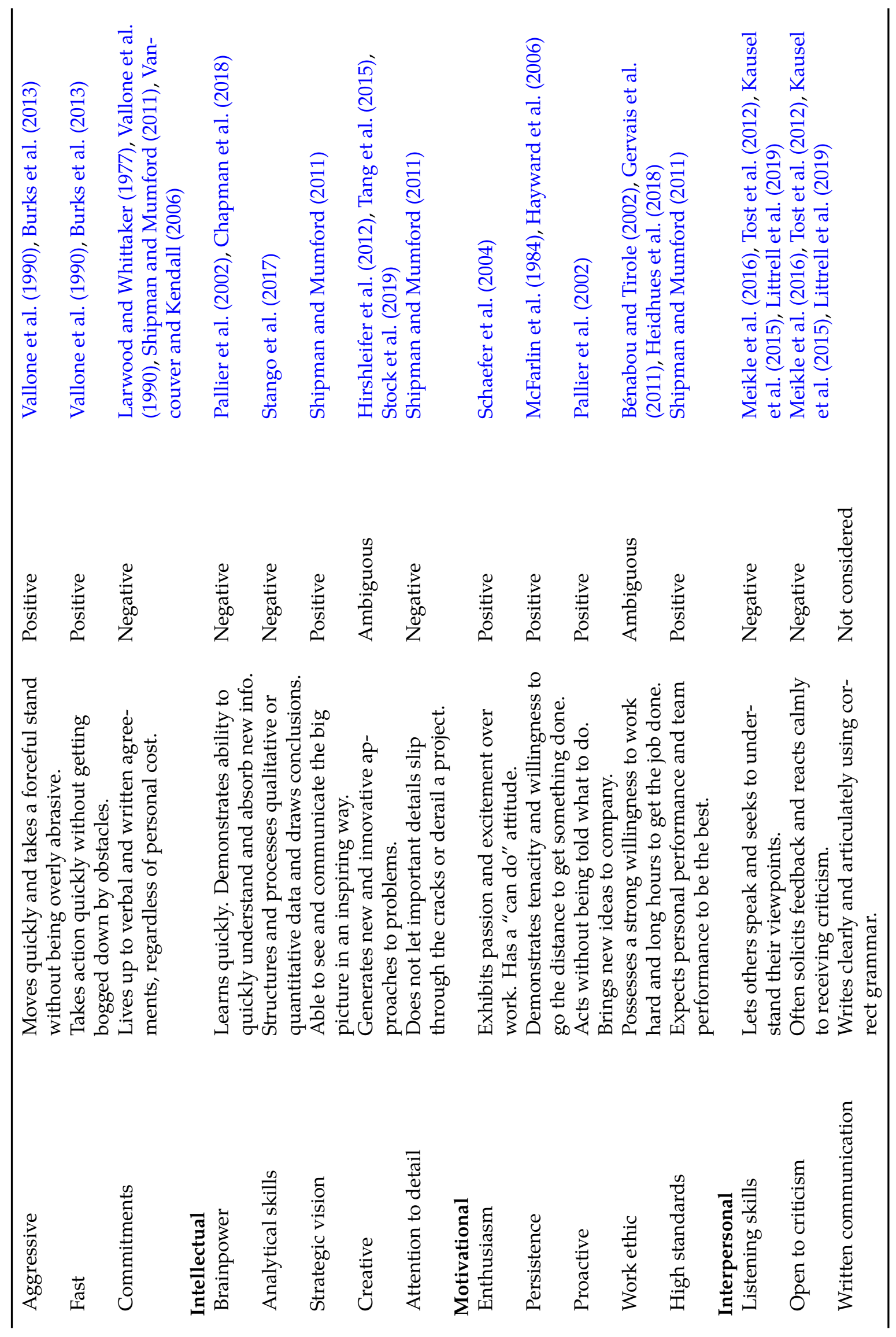




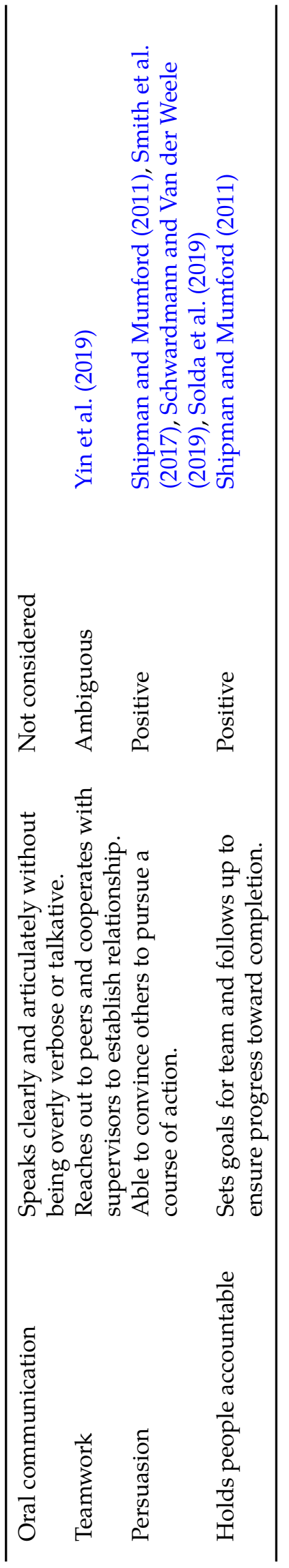




\section{B. Kaplan and Sorensen (2019) factor loadings}

This appendix shows Table 5 (Panel A) from Kaplan and Sorensen (2019) with factor loadings for the first four factors. Loadings with an absolute value less than 0.15 are left blank.

\begin{tabular}{lcccc}
\hline & Factor 1 & Factor 2 & Factor 3 & Factor 4 \\
\hline Hires A Players & 0.59 & & & \\
Develops People & 0.56 & 0.25 & & \\
Removes Underperformers & 0.53 & -0.17 & & -0.22 \\
Respect & 0.31 & 0.73 & & \\
Efficiency & 0.71 & & & -0.22 \\
Network & 0.64 & & & \\
Flexible & 0.54 & 0.38 & & \\
Integrity & 0.30 & 0.31 & & \\
Organization & 0.50 & & 0.44 & -0.23 \\
Calm & 0.44 & 0.33 & & \\
Aggressive & 0.68 & -0.43 & -0.26 & \\
Fast & 0.69 & -0.37 & -0.18 & \\
Commitments & 0.70 & & & -0.21 \\
Brainpower & 0.52 & & 0.33 & 0.43 \\
Analytical Skills & 0.54 & & 0.56 & 0.25 \\
Strategic Vision & 0.58 & -0.16 & & 0.46 \\
Creative & 0.52 & & & 0.39 \\
Attention to Detail & 0.40 & & 0.46 & -0.27 \\
Enthusiasm & 0.55 & 0.24 & -0.44 & \\
Persistence & 0.66 & -0.16 & & \\
Proactive & 0.74 & -0.26 & -0.20 & \\
Work Ethic & 0.57 & & & \\
High Standards & 0.73 & -0.17 & & \\
Listening Skill & 0.39 & 0.62 & & \\
Open to Criticism & 0.41 & 0.65 & & \\
Oral Communication & 0.49 & 0.16 & -0.16 & 0.19 \\
Teamwork & 0.48 & 0.61 & & \\
Persuasion & 0.60 & & -0.37 & 0.18 \\
Holds People Accountable & 0.66 & -0.21 & & -0.27 \\
\hline
\end{tabular}




\section{Figure 1: Distribution across industries}

This figure depicts the distribution of 78 firms by industrial sectors according to the Global Industry Classification Standard (GICS) by MSCI.

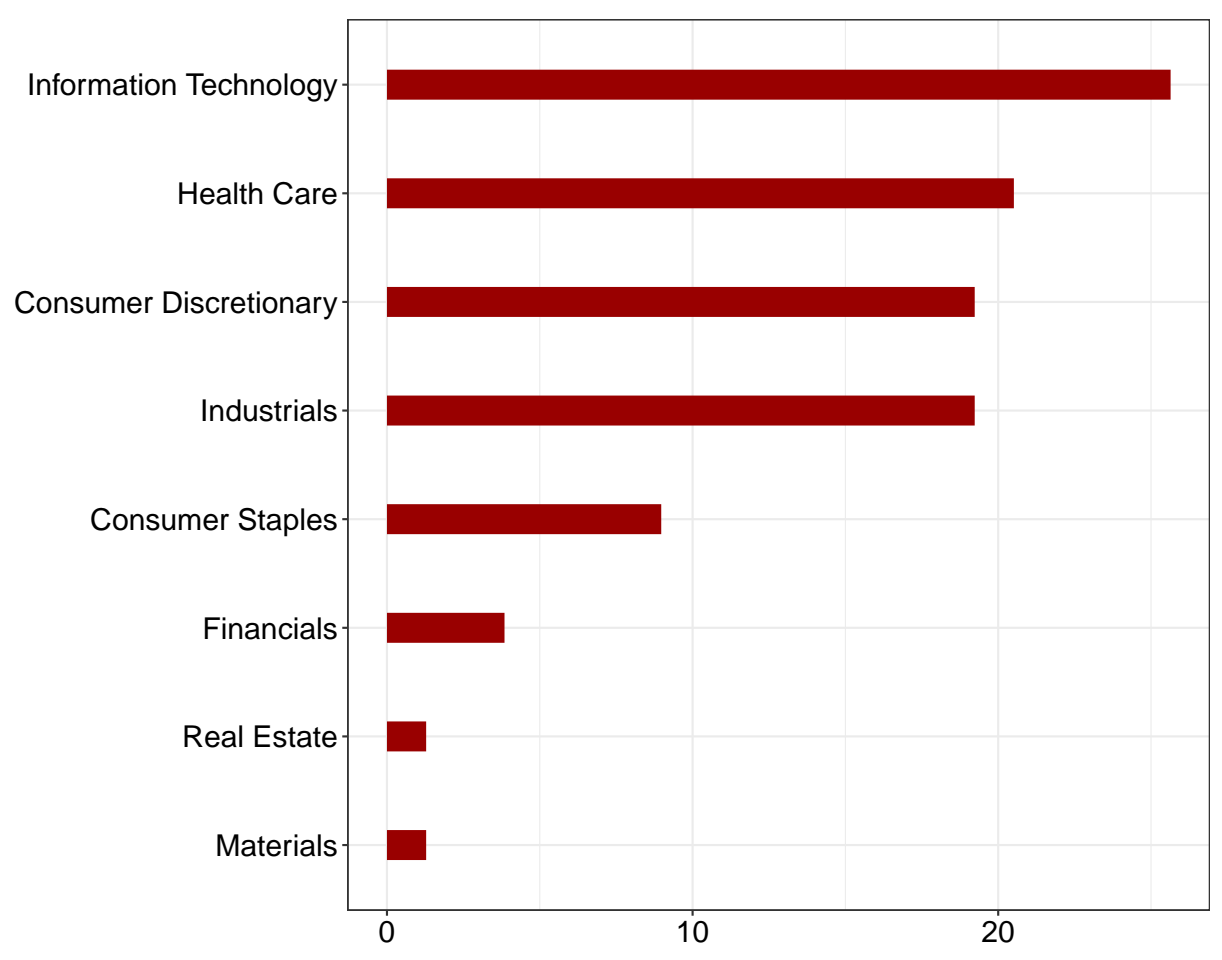




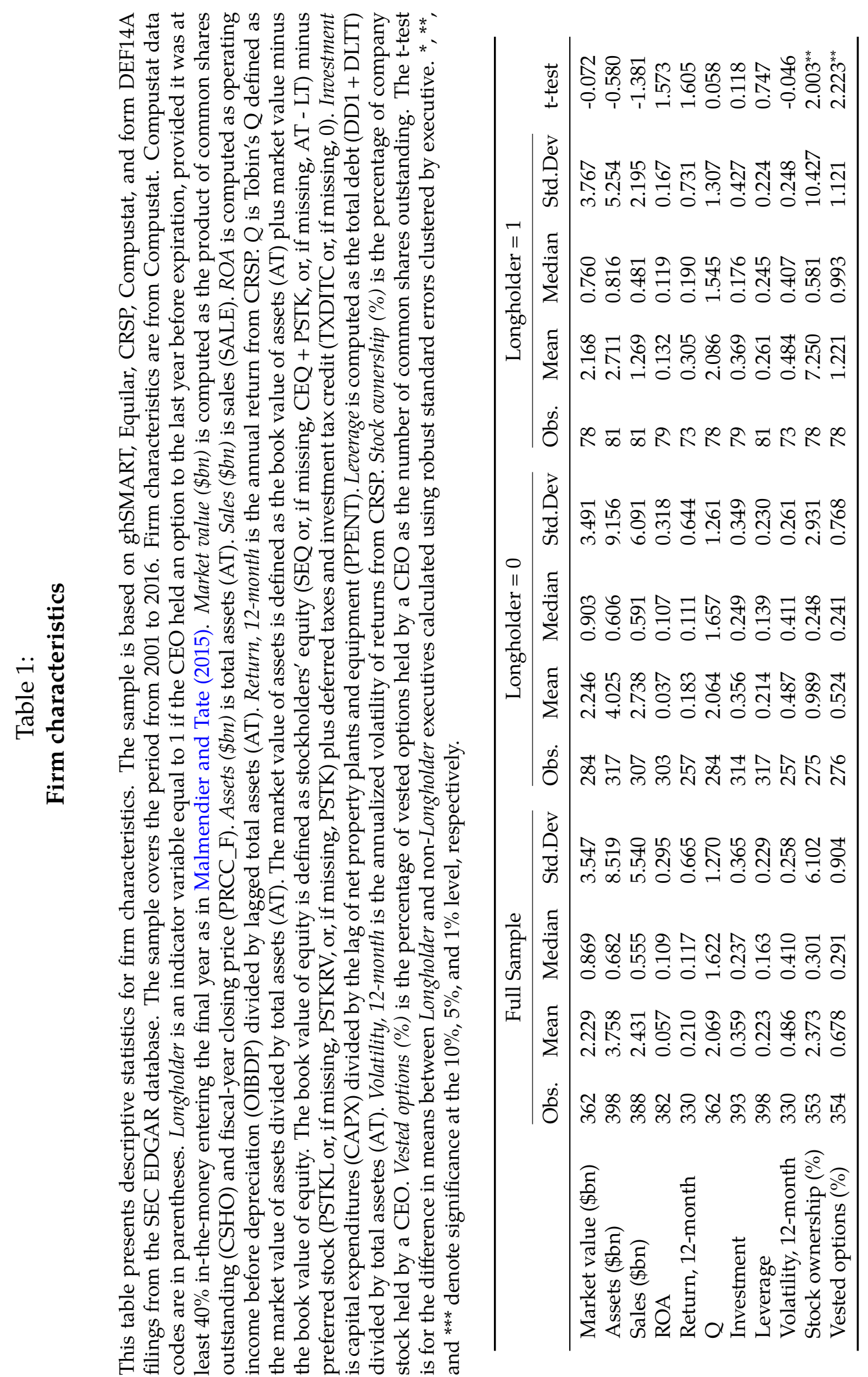




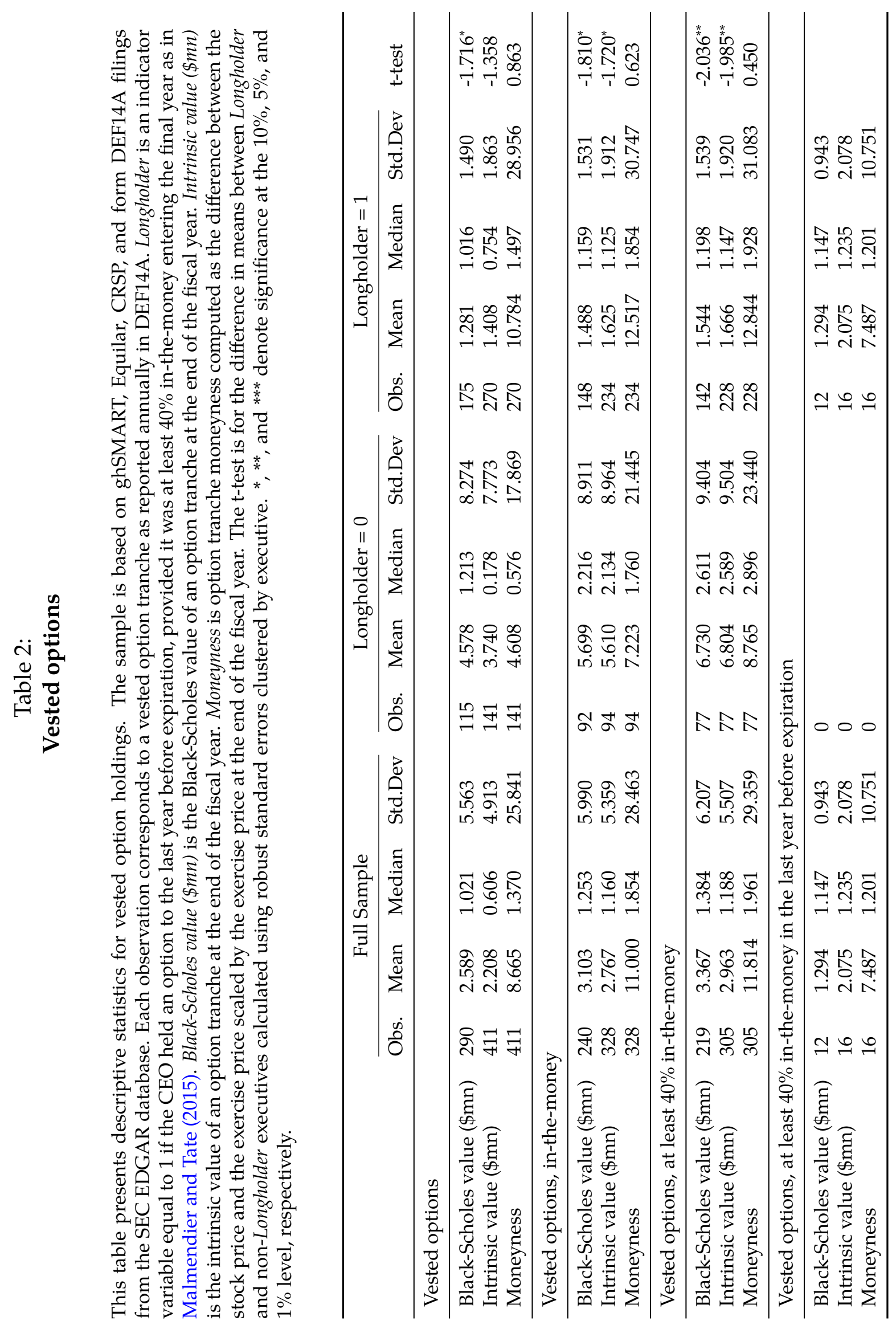




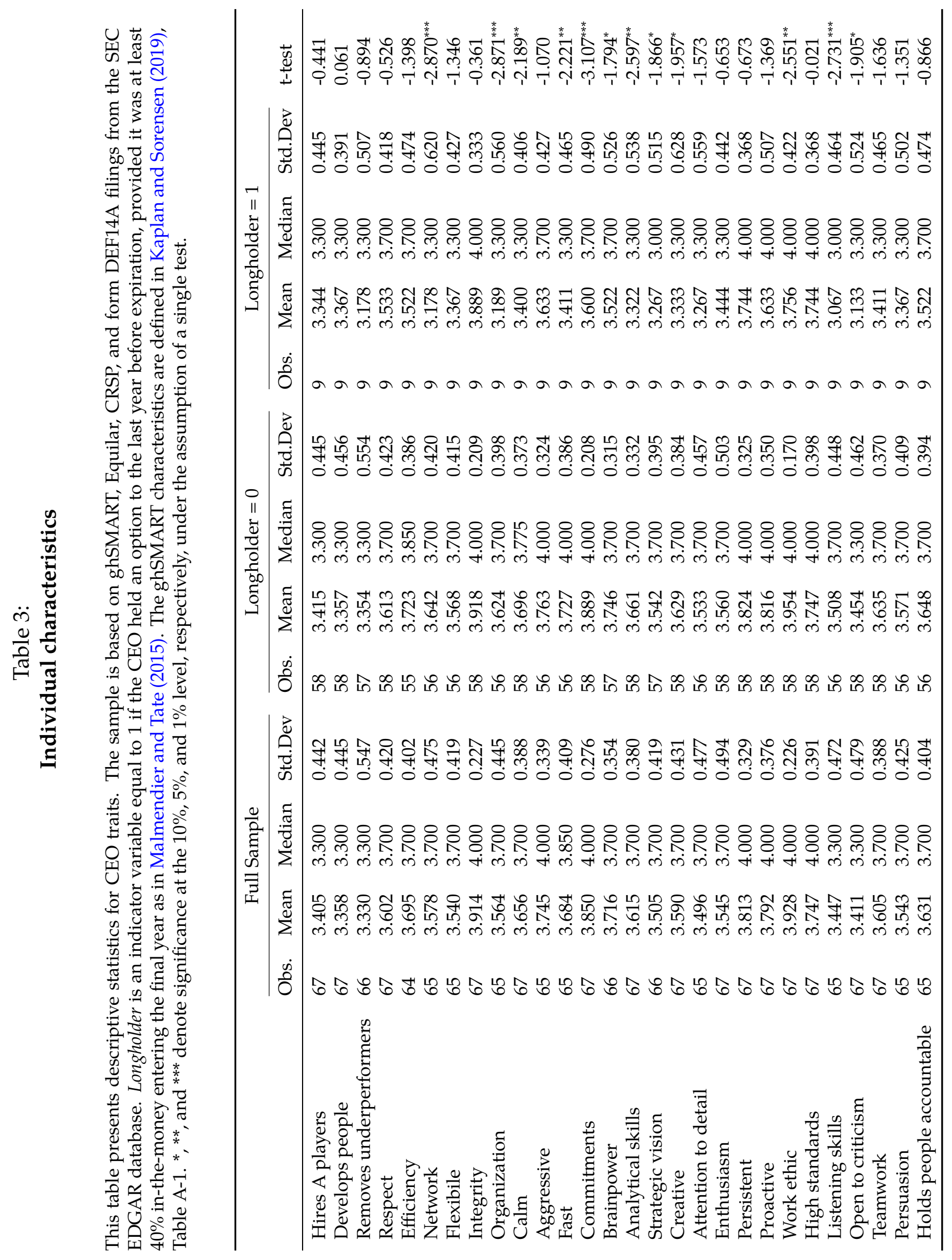


Table 4:

\section{Individual characteristics and EPS forecasts}

Each entry presents a linear regression of the CEO overconfidence measure-Longholder, High Forecast, or Point Estimate - on the specified characteristic. We present regression results for Longholder for comparability. High Forecast is an indicator variable that equals 1 when a firm's EPS forecat exceeds the realized EPS as in Otto (2014). If a firm provides an EPS range forecast, this indicator variable is 1 when the lower bound of the range exceeds the realized EPS. Point Estimate is an indicator variable that equals 1 when a firm provides a point EPS forecast, and 0 when it provides a range EPS forecast. EPS forecasts and realizations are from IBES. Beta is the coefficient on the characteristic. The $p$-value is the statistical significance of this coefficient calculated using robust standard errors clustered by executive. The number of observations in each regression is indicated in square brackets. The ghSMART characteristics are defined in Kaplan and Sorensen (2019), Table A-1. * **, and ${ }^{* * *}$ denote significance at the $10 \%, 5 \%$, and $1 \%$ level, respectively, under the assumption of a single test.

\begin{tabular}{|c|c|c|c|c|c|c|c|c|c|}
\hline & \multicolumn{3}{|c|}{ Longholder } & \multicolumn{3}{|c|}{ High Forecast } & \multicolumn{3}{|c|}{ Point Estimate } \\
\hline & Beta & Obs & $p$-val & Beta & Obs & $p$-val & Beta & Obs & $p$-val \\
\hline Hires A players & -0.042 & [67] & 0.661 & -0.093 & [216] & $0.072^{*}$ & -0.021 & [216] & 0.788 \\
\hline Develops people & 0.006 & [67] & 0.952 & -0.043 & [212] & 0.447 & -0.051 & [212] & 0.614 \\
\hline Removes underperformers & -0.070 & [66] & 0.375 & -0.115 & [216] & $0.004^{* * *}$ & 0.057 & [216] & 0.416 \\
\hline Respect & -0.053 & [67] & 0.600 & 0.004 & [212] & 0.935 & -0.057 & [212] & 0.384 \\
\hline Efficiency & -0.152 & [64] & 0.167 & -0.220 & [216] & $0.000^{* * *}$ & 0.054 & [216] & 0.594 \\
\hline Network & -0.249 & [65] & $0.006^{* * *}$ & -0.058 & [216] & 0.397 & 0.104 & [216] & 0.378 \\
\hline Flexibile & -0.139 & [65] & 0.183 & -0.058 & [216] & 0.188 & -0.006 & [216] & 0.927 \\
\hline Integrity & -0.068 & [67] & 0.719 & -0.122 & [216] & 0.464 & -0.087 & [216] & 0.575 \\
\hline Organization & -0.266 & [65] & $0.006^{* * *}$ & -0.080 & [216] & 0.133 & -0.073 & [216] & 0.496 \\
\hline Calm & -0.232 & [67] & $0.032^{* *}$ & -0.010 & [216] & 0.896 & 0.068 & [216] & 0.411 \\
\hline Aggressive & -0.137 & [65] & 0.289 & -0.159 & [216] & 0.121 & 0.064 & [216] & 0.640 \\
\hline Fast & -0.230 & [65] & $0.030^{* *}$ & -0.037 & [216] & 0.632 & 0.262 & [216] & $0.002^{* * *}$ \\
\hline Commitments & -0.448 & [67] & $0.003^{* * *}$ & -0.327 & [216] & $0.065^{*}$ & 0.224 & [216] & 0.240 \\
\hline Brainpower & -0.213 & [66] & $0.078^{*}$ & -0.240 & [216] & $0.000^{* * *}$ & -0.038 & [216] & 0.784 \\
\hline Analytical skills & -0.277 & [67] & $0.012^{* *}$ & -0.094 & [216] & 0.340 & 0.006 & [216] & 0.970 \\
\hline Strategic vision & -0.187 & [66] & $0.067^{*}$ & -0.035 & [216] & 0.566 & 0.186 & [216] & $0.033^{* *}$ \\
\hline Creative & -0.188 & [67] & $0.055^{*}$ & -0.251 & [216] & $0.006^{* * *}$ & -0.129 & [216] & 0.387 \\
\hline Attention to detail & -0.142 & [65] & 0.121 & -0.192 & [216] & $0.000^{* * *}$ & -0.057 & [216] & 0.618 \\
\hline Enthusiasm & -0.056 & [67] & 0.516 & 0.006 & [212] & 0.932 & 0.064 & [212] & 0.485 \\
\hline Persistent & -0.087 & [67] & 0.504 & -0.291 & [216] & $0.010^{* * *}$ & -0.050 & [216] & 0.707 \\
\hline Proactive & -0.153 & [67] & 0.176 & -0.347 & [216] & $0.000^{* * *}$ & -0.190 & [216] & 0.288 \\
\hline Work ethic & -0.458 & [67] & $0.013^{* *}$ & -0.503 & [216] & 0.154 & 0.317 & [216] & $0.043^{* *}$ \\
\hline High standards & -0.002 & [67] & 0.983 & -0.571 & [216] & $0.000^{* * *}$ & -0.388 & [216] & $0.059^{*}$ \\
\hline Listening skills & -0.240 & [65] & $0.008^{* * *}$ & 0.018 & [212] & 0.658 & 0.010 & [212] & 0.873 \\
\hline Open to criticism & -0.165 & [67] & $0.061^{*}$ & 0.005 & [216] & 0.918 & -0.012 & [216] & 0.863 \\
\hline Teamwork & -0.176 & [67] & 0.107 & 0.005 & [216] & 0.938 & 0.027 & [216] & 0.761 \\
\hline Persuasion & -0.138 & [65] & 0.181 & -0.027 & [216] & 0.756 & 0.163 & [216] & 0.106 \\
\hline Holds people accountable & -0.093 & [65] & 0.390 & -0.231 & [212] & $0.001^{* * *}$ & -0.221 & [212] & $0.073^{*}$ \\
\hline
\end{tabular}




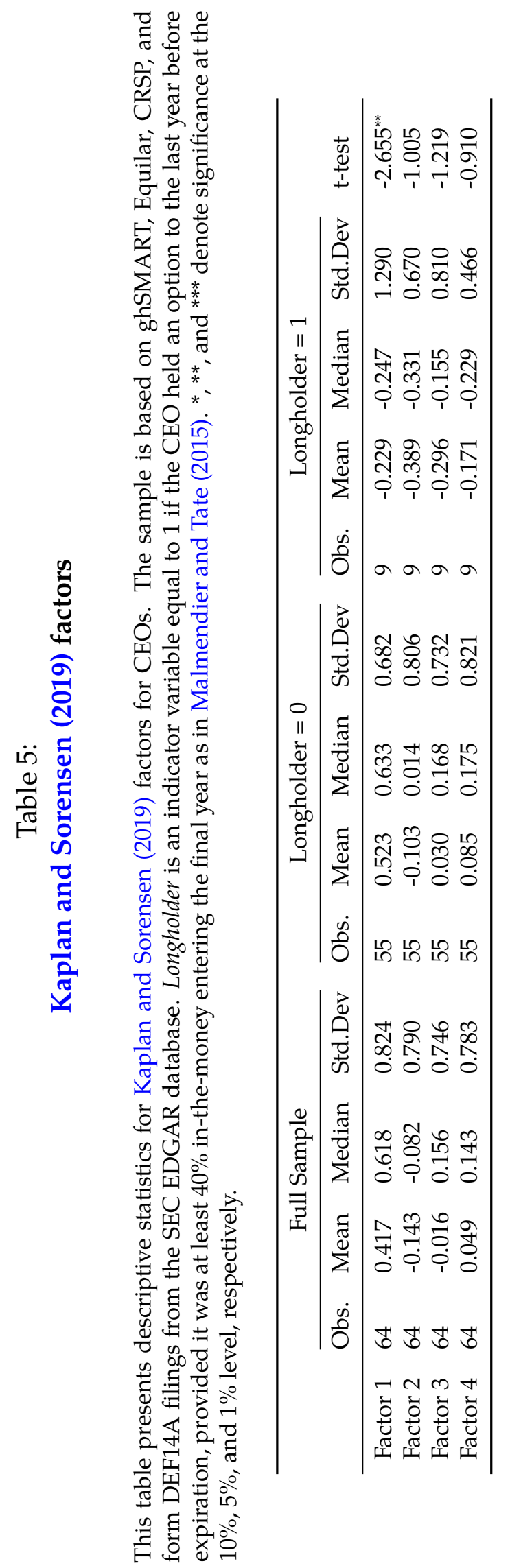


Table 6:

\section{CEO overconfidence and Kaplan and Sorensen (2019) factors}

This table reports estimates of the linear regressions of CEO overconfidence on Kaplan and Sorensen (2019) factors. The variables are defined in Table 3. Robust standard errors are in parentheses. ${ }^{*}, * *$, and ${ }^{* * *}$ denote significance at the $10 \%, 5 \%$, and $1 \%$ level, respectively.

\begin{tabular}{lccccc}
\hline & \multicolumn{5}{c}{ Longholder } \\
& $(1)$ & $(2)$ & $(3)$ & $(4)$ & $(5)$ \\
\hline Factor 1 & $-0.136^{* *}$ & & & & $-0.125^{* *}$ \\
& $(0.051)$ & & & & $(0.052)$ \\
Factor 2 & & -0.056 & & & -0.043 \\
& & $(0.056)$ & & & $(0.054)$ \\
Factor 3 & & & -0.072 & & -0.054 \\
& & & $(0.059)$ & & $(0.057)$ \\
Factor 4 & & & & -0.051 & -0.051 \\
& & & & $(0.056)$ & $(0.054)$ \\
\hline $\mathrm{R}^{2}$ & 0.102 & 0.016 & 0.023 & 0.013 & 0.137 \\
Obs. & 64 & 64 & 64 & 64 & 64 \\
\hline
\end{tabular}




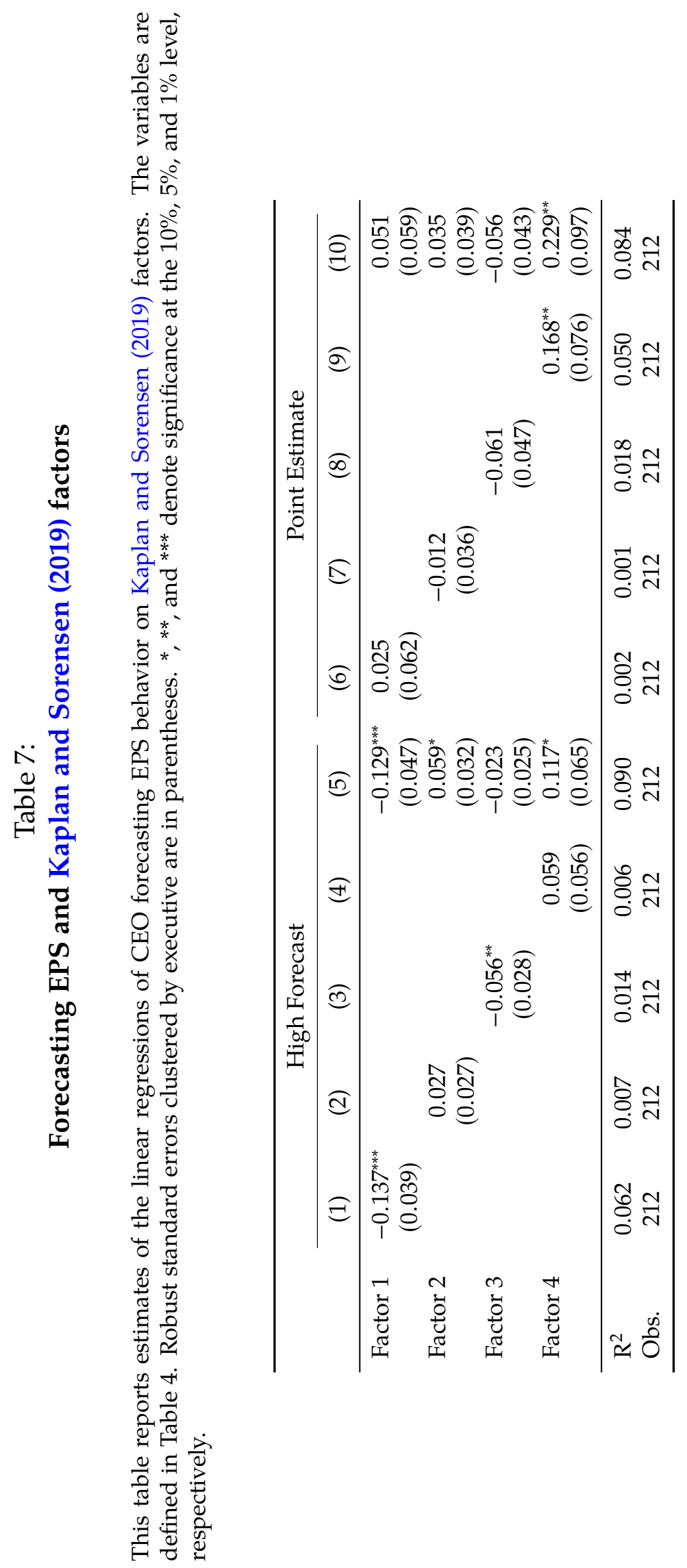




\section{Table 8:}

\section{Summary statistics for investment sensitivity analyses}

This table presents descriptive statistics for the investment-cash flow sensitivity analyses. The sample is based on ghSMART, Equilar, CRSP, Compustat, and form DEF14A filings from SEC EDGAR database. The sample covers the period from 2001 to 2016. Firm characteristics are from Compustat. Compustat data codes are in parentheses. The top panel reports average firm characteristics. Obs. per firm is the number of observations by firm. Avg. Market value ( $\$ b n)$ is the average market capitalization by firm computed as the product of common shares outstanding (CSHO) and fiscal-year closing price (PRCC_F). Avg. Leverage is the average leverage by firm computed as the total debt (DD1 + DLTT) divided by total assetes (AT). Avg. ROA is the average return on assets by firm computed as operating income before depreciation (OIBDP) divided by lagged total assets (AT). Longholder and Factor 1-4 are defined in Table 3. The investment-cash flow sensitivity analyses variables are defined as in Malmendier and Tate (2015). Investment is capital expenditures (CAPX) divided by the lag of net property plants and equipment (PPENT). $Q$ is Tobin's $Q$ defined as the market value of assets divided by total assets (AT). The market value of assets is defined as the book value of assets (AT) plus market value minus the book value of equity. The book value of equity is defined as stockholders' equity (SEQ or, if missing, CEQ + PSTK, or, if missing, AT - LT) minus preferred stock (PSTKL or, if missing, PSTKRV, or, if missing, PSTK) plus deferred taxes and investment tax credit (TXDITC or, if missing, 0). Size is the logarithm of total assets (AT). Cash flow is the sum of earnings (IB) and depreciation (DP) divided by the lag of net property plants and equipment (PPENT). Stock ownership is the fraction of company stock held by a CEO. Vested options is the number of vested options held by a CEO divided by the number of common shares outstanding. Efficient board size is an indicator variable equal to 1 if the board has between 4 and 12 members. Investment, $Q$, Size, Cash flow, Stock ownership, Vested options are winsorized at the 1st and 99th percentiles.

\begin{tabular}{lcccccccc} 
& Obs. & Mean & Std.Dev & p5 & p25 & p50 & p75 & p95 \\
\hline \multicolumn{7}{c}{ Average } & firm characteristics \\
\hline Obs. per firm & 78 & 4.500 & 3.194 & 1.000 & 2.000 & 4.000 & 6.000 & 10.150 \\
Avg. Market value $(\$ b n)$ & 78 & 1.808 & 2.803 & 0.030 & 0.230 & 0.656 & 2.013 & 6.033 \\
Avg. Leverage & 78 & 0.247 & 0.237 & 0.000 & 0.043 & 0.216 & 0.361 & 0.719 \\
Avg. ROA & 78 & 0.053 & 0.314 & -0.480 & 0.057 & 0.114 & 0.182 & 0.303 \\
\hline \multicolumn{7}{c}{ Summary statistics for investment-cash flow sensitivity } & analyses \\
\hline Longholder & 317 & 0.237 & 0.426 & 0.000 & 0.000 & 0.000 & 0.000 & 1.000 \\
Factor 1 & 351 & 0.333 & 0.837 & -1.188 & -0.218 & 0.517 & 1.018 & 1.485 \\
Factor 2 & 351 & -0.123 & 0.911 & -1.379 & -0.814 & -0.079 & 0.603 & 1.337 \\
Factor 3 & 351 & -0.163 & 0.818 & -1.399 & -0.642 & -0.155 & 0.413 & 0.995 \\
Factor 4 & 351 & 0.184 & 0.866 & -0.993 & -0.227 & 0.236 & 0.502 & 1.559 \\
Investment & 351 & 0.407 & 0.364 & 0.037 & 0.141 & 0.290 & 0.598 & 1.131 \\
Q & 351 & 2.098 & 1.212 & 0.942 & 1.206 & 1.677 & 2.620 & 4.641 \\
Size & 351 & 6.436 & 1.727 & 3.226 & 5.347 & 6.374 & 7.527 & 9.270 \\
Cash flow & 351 & 0.460 & 4.965 & -5.405 & 0.144 & 0.779 & 1.699 & 4.931 \\
Stock ownership & 351 & 0.036 & 0.076 & 0.000 & 0.001 & 0.004 & 0.016 & 0.244 \\
Vested options & 351 & 0.006 & 0.010 & 0.000 & 0.000 & 0.002 & 0.008 & 0.024 \\
Efficient board size & 335 & 1.000 & 0.000 & 1.000 & 1.000 & 1.000 & 1.000 & 1.000 \\
\hline
\end{tabular}


Table 9:

\section{The sensitivity of investment to cash flow and Kaplan and Sorensen (2019) factors}

This table reports estimates of the linear regressions of investment on cash flow, CEO traits, cash flow interacted with CEO traits, control variables, control variables interacted with cash flow, year fixed effects, and year fixed effects interacted with cash flow. The variables are defined in Tables 3 and 8. Robust standard errors clustered by firm are in parentheses. ${ }^{*}, * *$, and ${ }^{* *}$ denote significance at the $10 \%, 5 \%$, and $1 \%$ level, respectively.

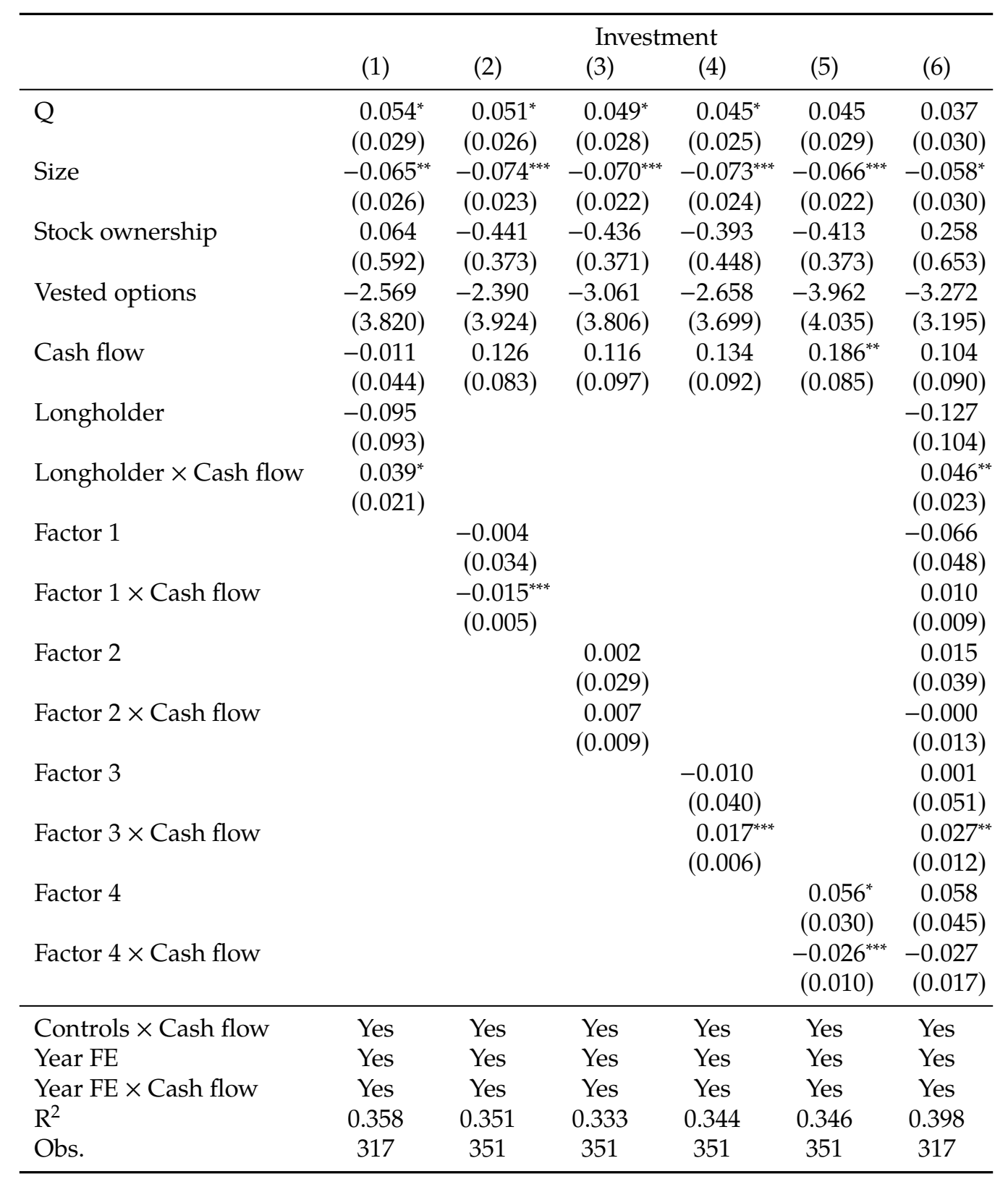

